\title{
SYNTHESIS OF ARYL (5-SUBSTITUTED BENZOFURAN-2-YL) CARBAMATE DERIVATIVES AS ANTIMICROBIAL AGENTS
}

\author{
SHANKAR BUDHWANI ${ }^{1 *}$, SHAILENDRA SHARMA ${ }^{2}$, NAVANATH KALYANE ${ }^{3}$
}

${ }^{1}$ Department of Pharmaceutical Chemistry, Faculty of Pharmaceutical Sciences, Jodhpur National University, Jodhpur, Rajasthan, India. ${ }^{2}$ Department of Pharmacy, Jodhpur Institute of Pharmacy, Jodhpur National University, Jodhpur, Rajasthan, India. ${ }^{3}$ Department of Pharmaceutical Chemistry, B.L.D.E.A'S College of Pharmacy, Bijapur, Karnataka, India. Email: shankarbudhwani2016@gmail.com

Received: 25 November 2016, Revised and Accepted: 20 December 2016

ABSTRACT

Objectives: Benzofurans are very interesting heterocycles, which are available in nature and show a wide range of pharmacological activities, viz., antifungal, antibacterial, antitumor, antimalarial and antioxidant activity.

Methods: A convenient method for the preparation of aryl (5-substituted benzofuran-2-yl) carbamate derivatives 6a-6j has been developed. The target compounds 1-(5-nitrobenzofuran-2-yl)-3-arylurea (6a-6e) and 1-(5-bromobenzofuran-2-yl)-3arylurea (6f-6j) have been prepared by reacting 5-nitrobenzofuran-2-carbonyl azide 5a or 5-bromobenzofuran-2-carbonyl azide 5b with substituted phenols in reasonable overall yields. All the synthesized compounds were characterized using Fourier transform infrared (FTIR), ${ }^{1} \mathrm{H}$ NMR and mass spectrometry and were subjected to antimicrobial screening against two Gram-positive bacteria (Staphylococcus aureus and Bacillus subtilis), two Gram-negative bacteria (Escherichia coli and Pseudomonas aeruginosa), and two fungi (Candida albicans and Aspergillus niger) using two-fold dilution method.

Results and Discussion: All the values of FTIR, ${ }^{1} \mathrm{H}$ NMR and mass spectra were found to be prominent. The results indicate that synthesized compound 6i showed potent antimicrobial activity comparable to standard.

Conclusion: The detailed synthesis, spectroscopic data, and antimicrobial activities of synthesized compounds were reported.

Keywords: Benzofuran, Antibacterial activity, Antifungal activity.

(C) 2017 The Authors. Published by Innovare Academic Sciences Pvt Ltd. This is an open access article under the CC BY license (http://creativecommons. org/licenses/by/4. 0/) DOI: http://dx.doi.org/10.22159/ajpcr.2017.v10i3.16332

\section{INTRODUCTION}

Benzofuran is one of the most important classes of fused ring heterocyclic compounds. The benzofuran derivatives are naturally occurring and possess many biological applications [1-3]. Angelicin, psoralen, and bergapten are the examples of naturally occurring benzofuran derivatives with biological applications [4-6]. The isolation of benzofuran derivatives from natural sources is laborious and timeconsuming. Hence, the synthetic chemists are interested in synthesizing the benzofuran derivatives. Numerous synthesized benzofuran derivatives were found to be biologically active [7-9]. Nowadays, many synthetic benzofurans are used as good inhibitor $[10,11]$, antimicrobial [12-14], anti-inflammatory [15,16], antiviral [17], antioxidant [18-21], antitumor [22], antiproliferative [23,24], and antialzheimer [25].

Fight against the microbes is never ending battle. The harmful microbe's poses biggest problem in the society as far as health and hygiene is concerned. Antimicrobial chemotherapy has been a leading cause for the dramatic rise of average life expectancy in the $20^{\text {th }}$ Century. However, disease-causing microbes that have become resistant to antibiotic drug therapy are an increasing public health problem. One part of the problems is that bacteria and other microbes that cause infections are remarkably resilient and have developed several ways to resist antibiotics and other antimicrobial drugs. Another part of the problem is due to increasing use, and misuse, of existing antibiotics in human and veterinary medicine and in agriculture. As the resistance to antimicrobial agents increasing day by day, it is very necessary to synthesize new compounds which will show less bacterial resistance and good inhibitory activity [26].
Hence, this paper highlights the simple convenient method of synthesis of benzofuran derivatives and antimicrobial evaluation. All the synthesized compounds were characterized using Fourier transform infrared (FTIR), ${ }^{1} \mathrm{H}$ NMR and mass spectrometry and were subjected to minimum inhibitory concentration (MIC) antimicrobial screening against two Gram-positive bacteria (Staphylococcus aureus and Bacillus subtilis), two Gram-negative bacteria (Escherichia coli and Pseudomonas aeruginosa), and two fungi (Candida albicans and Aspergillus niger) using two-fold dilution method.

\section{MATERIALS AND METHODS}

\section{Materials}

All chemicals were purchased from Sigma-Aldrich, SD Fine, Spectrochem, Merck, and Himedia. Yields refer to purified products and are not optimized. Melting points were determined on a VEEGOVMP I melting point apparatus and are uncorrected. IR spectra were recorded on a JASCO-FTIR 4100 spectrophotometer. ${ }^{1} \mathrm{H}$ NMR was recorded on a MERCURY VARIAN $400 \mathrm{MHz}$ instrument and chemical shifts $(\delta)$ were reported in parts per million with dimethyl sulfoxide as the solvent. Trimethylsilane was used as the internal standard for NMR. Mass spectroscopy (MS) analyses were done on an Applied Biosystem API 2000. Thin layer chromatography was performed on precoated aluminum plates with silica gel.

\section{Methods}

General method for synthesis of 5-substituted benzofuran-2-carbonyl azide (5a-5b): 5-substituted benzofuran-2-carbohydrazide 4a-4b ( 0.02 mole) was dissolved in a mixture of $30 \mathrm{ml}$ of acetic acid and $30 \mathrm{ml}$ of 1,4-dioxane and cooled to $0^{\circ} \mathrm{C}$ using ice salt bath. An ice cold 


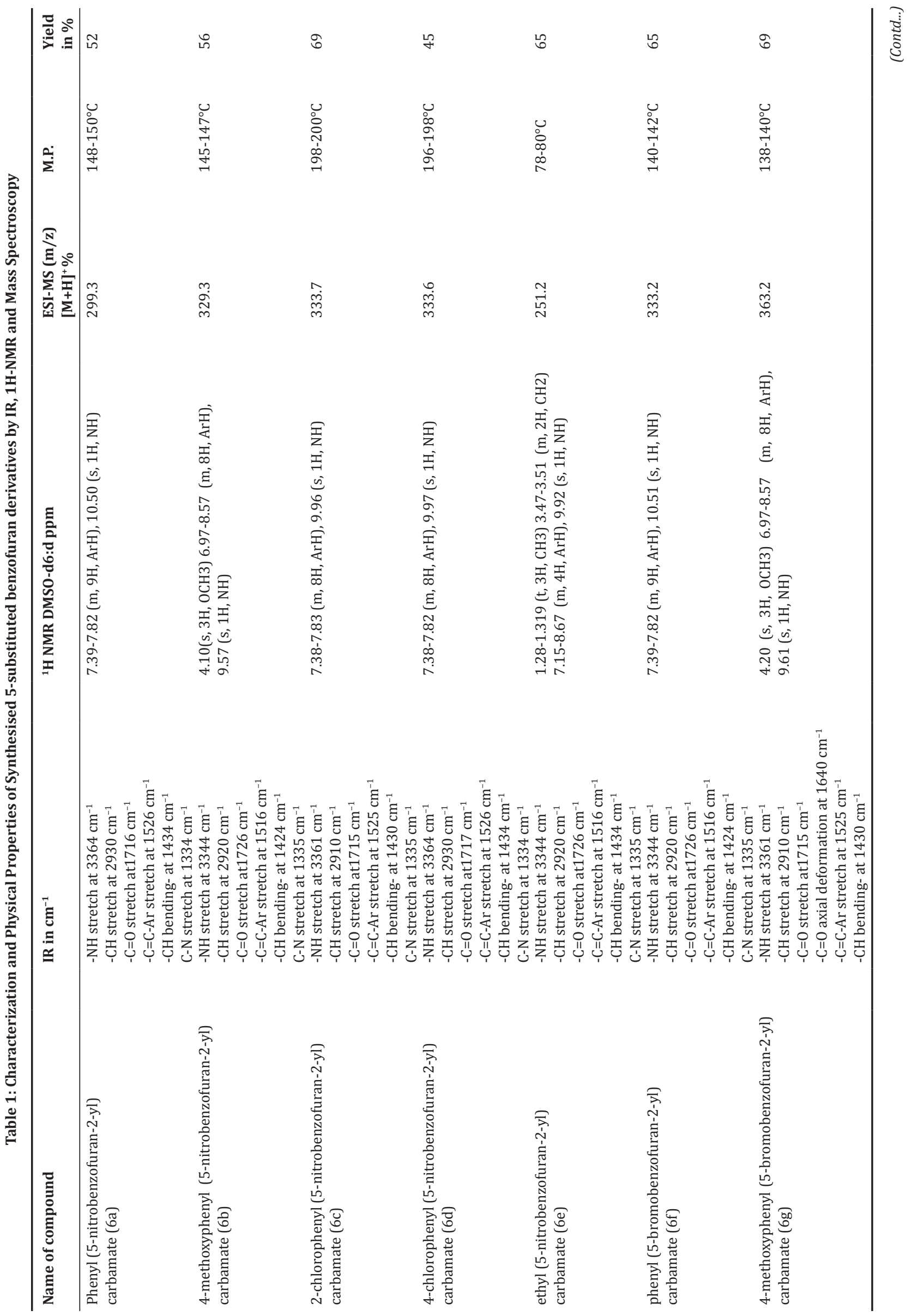




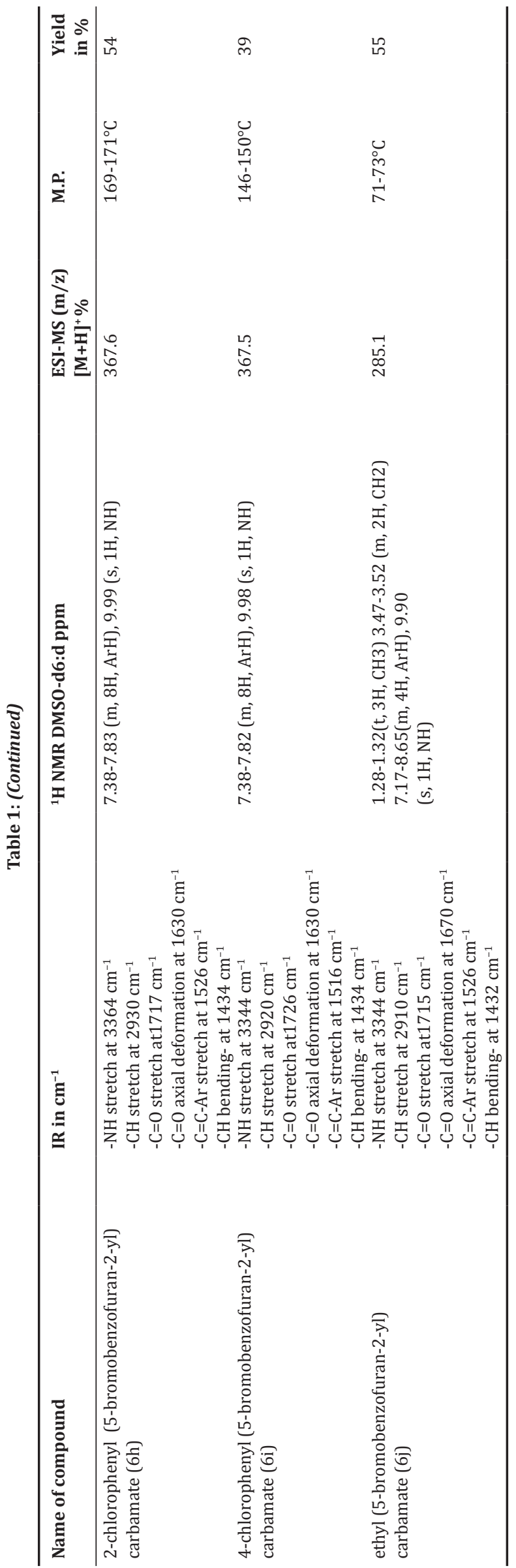

solution of sodium nitrite $(0.02$ mole) in water $(10 \mathrm{ml})$ was introduced in small portions with vigorous stirring while the temperature of the mixture was maintained below $2^{\circ} \mathrm{C}$. After addition was completed, the reaction mixture was allowed to stay at room temperature for $30 \mathrm{~min}$ and then solid was collected, washed with cold water. Solid was dried in desiccator and used immediately in next reaction [27].

General method for synthesis of aryl (5-substituted benzofuran-2-yl) carbamate derivatives (6a-6j: A mixture of 5-substituted benzofuran-2-carbonyl azide $5 \mathrm{a}-5 \mathrm{~b} \quad(5 \mathrm{mmol})$ and substituted phenol/ethanol ( $5 \mathrm{mmol}$ ) in dry toluene $(20 \mathrm{~mL})$ was refluxed for $4 \mathrm{hrs}$. The resulting solid, so formed, was collected and recrystallized from dioxane to give compounds $6 \mathrm{a}-6 \mathrm{j}$ as crystals.

\section{Antimicrobial activity}

Sterilized test tubes were numbered 1 through 9 . All of the following steps were carried out using aseptic technique. A solution of $0.2 \mathrm{ml}$ of 2000 $\mu \mathrm{g} / \mathrm{ml}$ test stock solution in dimethyl sulfoxide (DMSO) was transferred to a first sterile test tube containing $3.8 \mathrm{ml}$ of double strength nutrient broth to arrive $(100 \mu \mathrm{g} / \mathrm{ml})$ as initial dose and remaining test tubes 2-9 were filled with $2 \mathrm{ml}$ of double strength nutrient broth for the further dilution. DMSO as a control has no effect at $12.5 \%$ concentration against bacteria. These test tubes were serially diluted to give a concentration of $50,25,12.5,6.25,3.125,1.56,0.78$, and $0.39 \mu \mathrm{g} / \mathrm{ml}$.

One test tube with no test compound but with an equal volume of solvent DMSO (5\%) served as the vehicle control. One test tube with no test compound and no vehicle but only with nutrient media served as the positive control to ensure the growth property of media. To all the test tubes $0.1 \mathrm{ml}$ of suspension of bacteria (working inocula) were added, and the test tubes were incubated at $35-37^{\circ} \mathrm{C}$ for $24 \mathrm{hrs}$ in case of bacteria and the test tubes were incubated at $25-27^{\circ} \mathrm{C}$ for $48 \mathrm{hrs} \mathrm{in}$ case of fungi. The highest dilution of the test compound that completely inhibited the growth of test organism was considered as the MIC value of the test compound and was expressed in $\mu \mathrm{g} / \mathrm{ml}$ [26].

\section{RESULT AND DISCUSSION}

First, the following compounds were synthesized with resultant good yield such as synthesized 5-nitrobenzofuran-2-carbonyl azide 5a and 5 -bromobenzofuran-2-carbonyl azide $5 \mathrm{~b}$ from 5 -nitro benzofuran2-carbohydrazide 4a and 5-bromo benzofuran-2-carbohydrazide 4b by reported method and as per Fig. 1 . The target compounds $6 a-6 j$ were synthesized from 5-nitrobenzofuran-2-carbonyl azide $5 \mathrm{a}$ and 5 -bromobenzofuran-2-carbonyl azide $5 b$, respectively, by reacting with appropriate phenol. The structures of synthesized compounds were characterized by IR, ${ }^{1} \mathrm{H}$ NMR and mass spectrometry.

As from the synthesis of 5-nitro benzofuran-2-carbonyl azide (5a), the practical yield was found $55 \%$, MP recorded in the range of $94-96^{\circ} \mathrm{C}$.

Similarly, from the synthesis of 5-bromo benzofuran-2-carbonyl azide (5b), the practical was found $48 \%$, MP ranges from $131-133^{\circ} \mathrm{C}$.

The details of characterizations of synthesized 5 -substituted benzofuran derivatives and physical Properties as shown in Table 1.

\section{Antimicrobial activity}

The benzofuran derivatives 6a-6j were evaluated for antimicrobial activity against two Gram-positive bacteria S. aureus (ATCC 6538P) and B. subtilis (ATCC 6633); two Gram-negative bacteria E. coli (ATCC 8739) and P. aeruginosa (ATCC 9027); two fungal strains C. albicans (ATCC 10231) and A. niger (ATCC 9029). Azithromycin and fluconazole were used as standard controls. The minimum inhibition concentration as shown in Tables 2 and 3.

\section{CONCLUSION}

We report herein the synthesis, structural elucidation, and antimicrobial activities of 10 new benzofurans $6 \mathrm{a}-6 \mathrm{j}$. The structures 


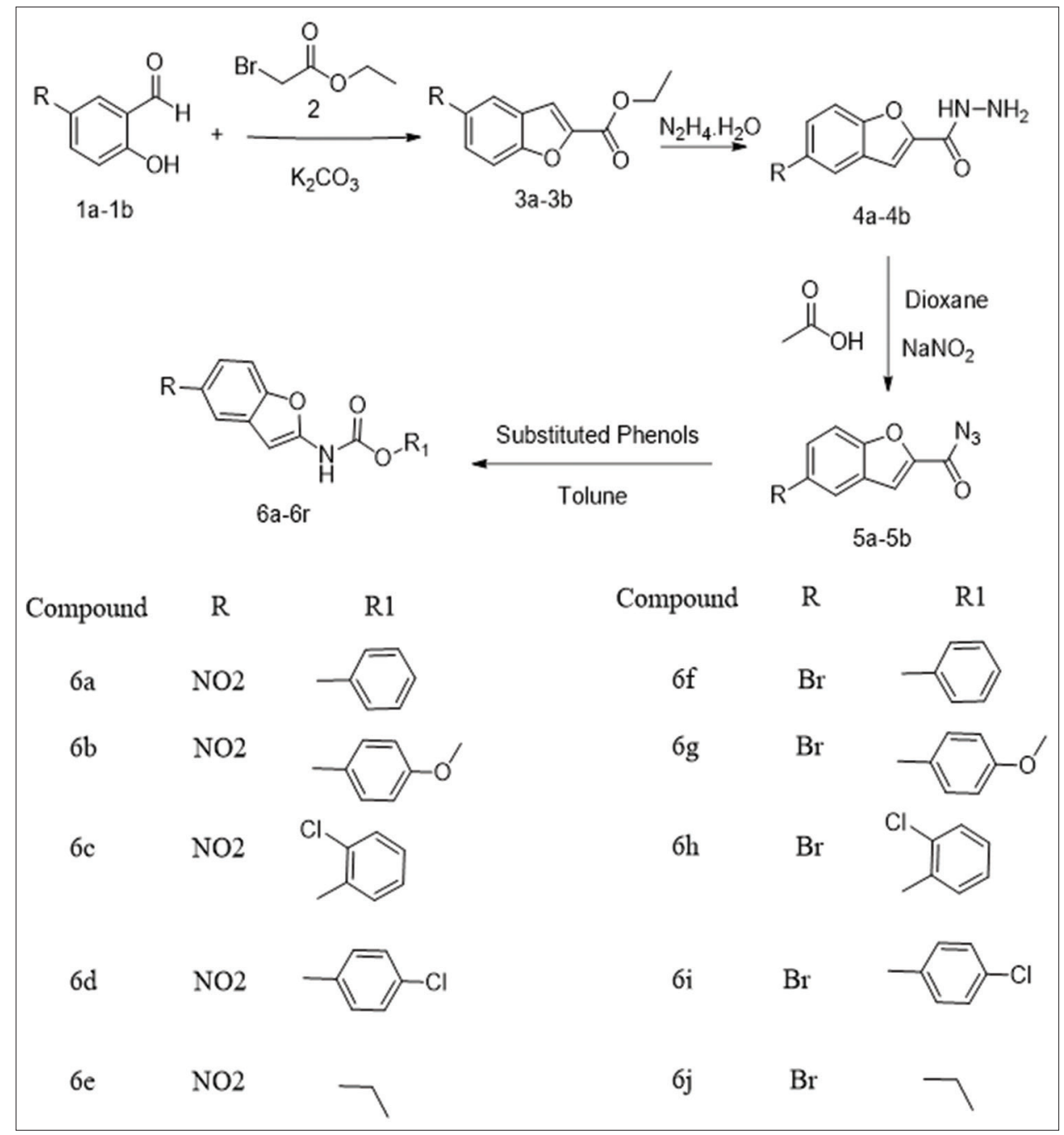

Fig. 1: General scheme of overall synthesis of 5-substituted benzofuran and their derivatives

Table 2: Minimum Inhibitory Concentration (MIC) of Test Compounds 6a to 6r against Staphylococcus aureus, Bacillus subtilis, Escherichia coli and Pseudomonas aeruginosa.

\begin{tabular}{|c|c|c|c|c|}
\hline \multirow[t]{2}{*}{ Test Comp. } & \multicolumn{4}{|l|}{ MIC $(\mu \mathrm{g} / \mathrm{ml})$} \\
\hline & Staphylococcus aureus & Bacillus Subtilis & Escherichia Coli & Pseudomonas aeruginosa \\
\hline $6 a$ & $>100$ & 100 & 100 & 100 \\
\hline $6 \mathrm{~b}$ & 50 & 25 & 25 & 50 \\
\hline $6 c$ & 50 & 25 & 50 & 50 \\
\hline $6 \mathrm{~d}$ & 25 & 6.25 & 6.25 & 6.25 \\
\hline $6 e$ & 50 & 50 & 100 & 50 \\
\hline $6 g$ & 25 & 25 & 50 & 25 \\
\hline $6 \mathrm{~h}$ & 50 & 25 & 25 & 50 \\
\hline $6 i$ & 25 & 12.5 & 6.25 & 12.5 \\
\hline $6 j$ & 100 & 50 & 50 & 100 \\
\hline $6 \mathrm{k}$ & 100 & 50 & 50 & 100 \\
\hline 61 & 100 & 50 & 100 & 100 \\
\hline $6 \mathrm{~m}$ & 50 & 50 & 50 & 100 \\
\hline $6 n$ & 50 & 50 & 50 & 50 \\
\hline $6 p$ & 12.5 & 1.56 & 6.25 & 12.5 \\
\hline $6 q$ & 25 & 12.5 & 12.5 & 12.5 \\
\hline $6 r$ & 25 & 12.5 & 12.5 & 6.25 \\
\hline Azithromycin & 0.39 & 1.56 & 12.5 & 6.25 \\
\hline
\end{tabular}

are fully supported by spectroscopic data. All the synthesized compounds were evaluated for their antimicrobial activities by the two-fold dilution method. Compounds 6d, 6f, 6g, and 6i exhibited reasonably high degree of antibacterial activities against $S$. aureus, 
Table 3: MIC of test compounds 6 a to $6 \mathrm{j}$ against $C$. albicans and A. niger

\begin{tabular}{lll}
\hline Test compound & MIC $(\mu \mathrm{g} / \mathrm{ml})$ & \\
\cline { 2 - 3 } & C. albicans & A. niger \\
\hline 6a & 25 & 12.5 \\
6b & 12.5 & 12.5 \\
6c & 50 & 25 \\
6d & 12.5 & 25 \\
6e & 25 & 12.5 \\
6f & 25 & 25 \\
6g & 25 & 25 \\
6h & 12.5 & 25 \\
6i & 12.5 & 25 \\
6j & 25 & 25 \\
Fluconazole & 12.5 & 12.5 \\
\hline
\end{tabular}

MIC: Minimum inhibitory concentration, C. albicans: Candida albicans, A. niger: Aspergillus niger

B. subtilis, E. coli, and P. aeruginosa. The other compounds exhibited varied degree of antibacterial activity. Compounds $6 \mathrm{~b}, 6 \mathrm{~d}, 6 \mathrm{e}, 6 \mathrm{~h}$, and $6 \mathrm{i}$ exhibited high degree of antifungal activities against both C. albicans and A. niger while the other compounds showed moderate to weak antifungal activity.

\section{REFERENCES}

1. Lee SK, Cui B, Mehta RR, Kinghorn AD, Pezzuto JM. Cytostatic mechanism and antitumor potential of novel 1hcyclopenta[b] benzofuran lignans isolated from Aglaia elliptica. Chem Biol Interact 1998; 115:215-28.

2. Janprasert J, Satasook C, Sukumalanand P, Champagne DE, Isman MB, Wiriyachitra P. Rocaglamide, a natural benzofuran insecticide from Aglaia odorata. Phytochemistry 1992;32:67-9.

3. Sundaram R, Ganesan R, Murugesan G. In vitro antiplasmodial activity of spiro benzofuran compound from mangrove plant of Southern India. Asian Pac J Trop Med 2012;5:358-61.

4. Yu B, Shi XJ, Zheng YF, Fang Y, Zhang E, Yu DQ. A novel $[1,2,4]$ triazolo [1,5-a] pyrimidine-based phenyl-linked steroid dimer: Synthesis and its cytotoxic activity. Eur J Med Chem 2013;69:323-30.

5. Panno ML, Giordano F, Mastroianni F, Palma MG, Bartella V, Carpino A, et al. Breast cancer cell survival signal is affected by bergapten combined with an ultraviolet irradiation. FEBS Lett 2010;584(11):2321-6.

6. Hsieh MJ, Chen MK, Yu YY, Sheu GT, Chiou HL. Psoralen reverses docetaxel-induced multidrug resistance in A549/D16 human lung cancer cells lines. Phytomedicine 2014;21(7):970-7.

7. Hassan GS, Abou-Seri SM, Kamel G, Ali MM. Celecoxib analogs bearing benzofuran moiety as cyclooxygenase-2 inhibitors: Design, synthesis and evaluation as potential antiinflammatory agents. Eur J Med Chem 2014; 76:482-93.

8. Sashidhara KV, Modukuri RK, Sonkar R, Rao KB, Bhatia G. Hybrid benzofuran-bisindole derivatives: New prototypes with promising antihyperlipidemic activities. Eur J Med Chem 2013;68:38-46.

9. El-Sawy ER, Ebaid MS, Abo-Salem HM, Al-Sehemi AG, Mandour AH. Synthesis, anti-inflammatory, analgesic and anticonvulsant activities of some new 4,6-dimethoxy-5-(heterocycles)benzofuran starting from naturally occurring visnagin. Arab J Chem 2012. Available from: http:// www.dx.doi.org/10.1016/j.arabjc.2012.12.041.

10. Wu J, Li Y, Chen K, Jiang $\mathrm{H}, \mathrm{Xu} \mathrm{MH}$, Liu D. Identification of benzofuran-3-yl(phenyl)methanones as novel SIRT1 inhibitors:
Binding mode, inhibitory mechanism and biological action. Eur J Med Chem 2013;60:441-50.

11. Xiang Y, Hirth B, Asmussen G, Biemann HP, Bishop KA, Good A, et al. The discovery of novel benzofuran-2-carboxylic acids as potent Pim-1 inhibitors. Bioorg Med Chem Lett 2011;21(10):3050-6.

12. Jiang X, Liu W, Zhang W, Jiang F, Gao Z, Zhuang H, et al. Synthesis and antimicrobial evaluation of new benzofuran derivatives. Eur J Med Chem 2011;46(8):3526-30.

13. Shankerrao S, Bodke YD, Santoshkumar S. Synthesis and antimicrobial activity of some imidazothiazole derivatives of benzofuran. Arab J Chem 2012. Available from: http://www.dx.doi.org/10.1016/j. arabjc. 2012.10.018.

14. Kirilmis C, Ahmedzade M, Servi S, Koca M, Kizirgil A, Kazaz C. Synthesis and antimicrobial activity of some novel derivatives of benzofuran: Part 2. The synthesis and antimicrobial activity of some novel 1-(1-benzofuran-2-yl)-2-mesitylethanone derivatives. Eur J Med Chem 2008;43(2):300-8.

15. Dawood KM, Abdel-Gawad H, Rageb EA, Ellithey M, Mohamed HA. Synthesis, anticonvulsant and anti-inflammatory evaluation of some new benzotriazole and benzofuran-based heterocycles. Bioorg Med Chem 2006; 14:3672-80

16. Santana L, Teijeira M, Uriarte E, Teran C, Lin $~$ ares B, Villar R. AM1 theoretical study, synthesis and biological evaluation of some benzofuran analogues of anti-inflammatory arylalkanoic acids. Eur J Pharm Sci 1999;7:161-6.

17. Malpani Y, Achary R, Kim SY, Jeong HC, Kim P, Han SB, et al. Efficient synthesis of $3 \mathrm{H}, 3$ ' $\mathrm{H}$-spiro[benzofuran-2,1'-isobenzofuran]3,3'-dione as novel skeletons specifically for influenza virus type B inhibition. Eur J Med Chem 2013;62:534-44.

18. Rangaswamy J, Kumar HV, Harini ST, Naik N. Synthesis of benzofuran based 1,3,5-substituted pyrazole derivatives: As a new class of potent antioxidants and antimicrobials-a novel accost to amend biocompatibility. Bioorg Med Chem Lett 2012;22:4773-7.

19. Rangaswamy J, Kumar HV, Harini ST, Naik N. Functionalized 3-(benzofuran-2-yl)-5-(4-methoxyphenyl)-4,5-dihydro-1h-pyrazole scaffolds: A new class of antimicrobials and antioxidants. Arab J Chem 2013. Available from: http://www.dx.doi.org/10.1016/j. arabjc.2013.10.012.

20. Yamuna AJ, Vaidya VP, Shruthi EK, Mahadevan M. Synthesis, characterization and biological activities of some benzofuropyrimidine derivatives. Int J Pharm Pharm Sci 2013;5(2):450-5.

21. Naik NH, Kumar V, Dias SM, Swamy JR. Novel 4-methoxy-2-acetyl benzofuran based chalcones: A new perceptivity into their antioxidant potentials. Int J Pharm Pharm Sci 2013;5(1):242-7.

22. Galal SA, Abd El-All AS, Abdallah MM, El-Diwani HI. Synthesis ofpotent antitumor andantiviral benzofuran derivatives. Bioorg Med Chem Lett 2009;19:2420-8.

23. Hranjec M, Sovic I, Ratkaj I, Pavlovic G, Ilic N, Valjalo L, et al. Antiproliferative potency of novel benzofuran-2-carboxamides on tumour cell lines: Cell death mechanisms and determination of crystal structure. Eur J Med Chem 2013;59(9):111-9.

24. Parekh S, Bhavsar D, Savant M, Thakrar S, Bavishi A, Parmar M. Synthesis of some novel benzofuran-2-yl (4,5-dihyro-3,5-substituted diphenylpyrazol-1-yl) methanones and studies on the antiproliferative effects and reversal of multidrug resistance of human MDR1-gene transfected mouse lymphoma cells in vitro. Eur J Med Chem 2011;46:1942-8.

25. Ono M, Kung MP, Hou C, Kung HF. Benzofuran derivatives as A betaaggregate-specific imaging agents for Alzheimer's disease. Nucl Med Biol 2002;29(6):633-42

26. Sable PN, Ganguly S, Chaudhari PD. An efficient one-pot threecomponent synthesis and antimicrobial evaluation of tetra substituted thiophene derivatives. Chin Chem Lett 2014;25:1099-103.

27. Madaan P, Tyagi VK. Quaternary pyridinium salts: A review. J Oleo Sci 2008;57(4):197-215. 